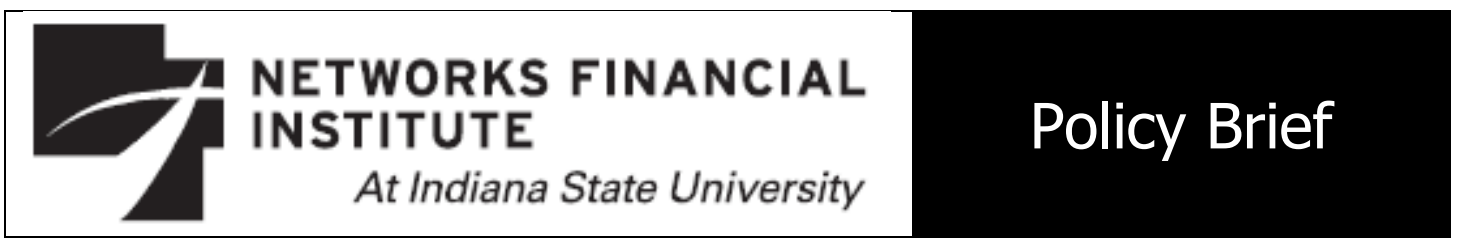

2014-PB-03

April 2014

\title{
INSURANCE CONTRACTS AND DERIVATIVES THAT SUBSTITUTE FOR THEM: HOW AND WHERE SHOULD THEIR SYSTEMIC AND NONPERFORMANCE RISKS BE REGULATED?
}

\section{Edward J. Kane}

Abstract: Traditionally, individual states have shared responsibility for regulating the US insurance industry. The Dodd-Frank Act changes this by tasking the Federal Reserve with regulating the systemic risks that particularly large insurance organizations might pose and assigning the regulation of swap-based substitutes for insurance and reinsurance products to the SEC and CFTC. This paper argues that prudential regulation of large insurance firms and weaknesses in federal swaps regulation could reduce the effectiveness of state-based systems for protecting policyholders and taxpayers from nonperformance in the insurance industry. Swap-based substitutes for traditional insurance and reinsurance contracts offer protection sellers a way to transfer responsibility for guarding against nonperformance into potentially lesseffective hands. The CFTC and SEC lack the focus, expertise, experience, and resources to manage adequately the ways that swaps transactions can affect US taxpayers' equity position in global safety nets, while regulators at the Fed refuse to recognize that conscientiously monitoring accounting capital at financial holding companies will not adequately protect taxpayers and policyholders until and unless it is accompanied by severe penalties for managers that willfully hide their firm's exposure to destructive tail risks.

About the Author: Edward J. Kane is Professor of Finance at Boston College. Ed Kane is a past president and fellow of the American Finance Association, a former Guggenheim fellow, and a Research Associate of the National Bureau of Economic Research. He serves on the editorial boards of seven professional journals. A founding member of the Shadow Financial Regulatory Committee, Professor Kane rejoined this committee in the summer of 2005. He also served for twelve years as a Trustee and member of the Finance Committee of Teachers Insurance. Currently, he consults for the World Bank and is a Senior Fellow in the FDIC's Center for Financial Research. He is a Senior Fellow of Networks Financial Institute.

Keywords: Dodd-Frank Act, systemic risk, nonperformance risk, regulatory culture, financial reform

JEL classification: E61, G21, G22, G28, K42

The views expressed are those of the individual author and do not necessarily reflect official positions of Networks Financial Institute. For helpful comments on these ideas, the author is grateful to Robert Dickler, Rex du Pont, Stephen Kane, and Jack Tatom. Please address questions regarding content to Edward Kane at edward.kane@bc.edu. Any errors or omissions are the responsibility of the author.

NFI working papers and other publications are available on NFI's website (www.networksfinancialinstitute.org). Click "Research" and then "Publications/Papers." 


\section{INSURANCE CONTRACTS AND DERIVATIVES THAT SUBSTITUTE FOR THEM: HOW AND WHERE SHOULD THEIR SYSTEMIC AND NONPERFORMANCE RISKS BE REGULATED?}

For federal regulators, the Dodd-Frank Act (DFA) of 2010 resembles an earthquake so massive that its aftershocks threaten to go on forever. The overarching purpose of this legislation is to end the perception that very large financial organizations can and do make themselves economically, politically, and administratively so difficult to fail and unwind that their liabilities implicitly enjoy near-perfect government guarantees. To create at least the appearance of progress on this herculean task, US and foreign regulators are trying simultaneously to re-forge national systems of balance-sheet requirements, activity constraints and information flows and to reconcile the new systems with still-evolving cross-border agreements for monitoring and unwinding the affairs of globally important firms.

This paper ties a difficult-to-unwind (DTU) firm's systemic risk to its ability to command safety-net support by means of a politically coerced "taxpayer put." This ability varies across firms, but the value of any DTU institution's taxpayer put grows with the size of the risk of ruin its management can live with. As a firm makes itself more and more DTU, the taxpayer becomes more firmly an equity investor of last resort. For DTU firms, the value of safety-net access comes from managers' dual capacity to under-reserve for ruinous losses and to persuade government officials in difficult circumstances to make taxpayers cover obligations that their institution's asset value can no longer meet (Kane, 2010).

National regulatory systems are shaped by endless adaptation and negotiation between government officials and representatives of the industries being regulated (see, e.g. Kaiser, 2013). This paper stresses that in and across countries regulatory dealmaking is conditioned by: 
(1) inherited differences in the norms of contract-based national regulatory cultures, and (2) expanding opportunities to fashion swap contracts that substitute for instruments (such as bank deposits) whose signature purposes define the boundaries of existing regulatory jurisdiction.

The discussion highlights the dominant role accorded to states in regulating the US insurance industry (an industry to which the DFA offers little love) and the need to integrate federal regulation of swap-based substitutes for traditional insurance and reinsurance contracts into this state-based system. Whatever advantages swap-based substitutes offer protection buyers, for protection sellers they serve as a form of regulatory arbitrage that circumvents preexisting forms of supervisory discipline and transfers responsibility for guarding against seller nonperformance to less-experienced and usually under-budgeted hands. My concern is to underscore the tendency for authorities to "under-supervise" such regulatory arbitrage and to clarify how reframing insurance, reinsurance, and annuity commitments as swaps simultaneously generates performance risk and extends the institutional and geographic boundaries of the financial safety net.

I believe that US taxpayers would be better served if safety-net abuse were prosecuted as a felony and innovative financial instruments were routinely screened for their abusive potential. The screening could be assigned to a reconstituted and repurposed Office of Financial Research (OFR) whose task would be to identify the ways in which such innovations promise to reallocate supervisory responsibility, to conceal their issuer's nonperformance risk and risk of ruin, and to expand the taxpayer loss exposures these risks imply. Regulators and firms could be required to prepare and publish estimates of the incremental value of tail risks and to refocus examination and accounting activity to surface data needed to inform the estimation process, so that 
confidence intervals on the estimates developed become tight enough to encourage the Department of Justice to prosecute abusers.

As illustrated by the messy rescue of the American International Group (AIG) in 2008, when regulatory arbitrage opens gaps in information access and supervisory focus, authorities are apt to learn too late that safety-net arbitrageurs operating under their purview have taken ruinous risks. AIG rang up crippling losses in products that substituted for traditional forms of banking business, but the responsibility for supervising AIG on a consolidated basis lay with a clueless Office of Thrift Supervision rather than falling within the jurisdiction of the Federal Reserve who would have been better-equipped for the task.

To minimize incentive conflict, the OFR ought to focus on the detection of systemic risk and be kept free of specific regulatory responsibilities. To reduce bureaucratic recognition lags, each and every issuer of instruments that reallocate supervisory authority should be required to alert the OFR to investigate the risks we have enumerated as soon as its volume of trading in a jurisdiction-altering contract surpasses a de minimis level of activity. Authority to disallow or adjust the parameters of contracts that the OFR finds to be dangerous to counterparties or taxpayers could be assigned individually or collectively to various existing federal and state agencies, based on each agency's ability to demonstrate to the OFR its capacity to design and enforce a reliable system for monitoring and reserving for the risks and loss exposures the OFR calculates. An ancillary goal of the analysis is to warn that safety-net subsidies generated by swaps that substitute for insurance and reinsurance contracts must be monitored closely, but in ways that do not compromise traditional programs for minimizing non-performance risk that customers face in insurance policies in New York and other states. It is imperative that 
systemic-risk regulators help state agencies to supervise the pass-through of nonperformance risk to insurance contracts from insurance-firm swap and securities lending programs.

I. Differences in Regulatory Cultures for Different Contractual Forms of Protection $\underline{\text { Selling }}$

Anthropologists study how and why people living in different places develop idiosyncratic cultures. One way in which cultures differ from one another is in the languages and tools that residents employ. Conceiving of a region's laws as regulatory languages and government institutions as tools used to regulate the behavior of financial institutions leads to the narrower concept of a "regulatory culture." As traditional boundaries between institutions and markets melt away, differences in the tools and languages of sectoral and national regulatory cultures become more consequential (Kane, 2005).

Although banks and other financial institutions offer their customers similar wealthmanagement services, their corporate and regulatory cultures are very different. The principal tools of US bank regulation are on-site examinations, administrative orders, and agency-enforced balance-sheet restrictions. The principal tools for regulating activity in securities and derivatives contracts differ from this. In these sectors, regulators' main activities are to set fair-play standards of market conduct and information disclosure. Efforts to impose new standards or to correct violations are often delayed by having to weather industry-initiated challenges in state and federal courts.

Financial products typically offer customers some degree of protection against losses from adverse events. In the US, individuals and corporations can buy specific protection in 
diverse ways. Protections can be crafted in at least three different contractual forms: as an insurance contract, as a swap contract, or as a contingent guarantee. Although each of these contracts is bilateral in form, third-party regulation plays an indispensable role in generating trust and enforcing fair and timely contract performance. But in the US and elsewhere, the tools, expertise, and traditions that have developed in each contract's regulatory culture differ in important ways.

Like most other corporations, protection sellers routinely seek to conceal unfavorable or embarrassing information from outsiders. Customers and counterparties cannot easily surface negative information without the help of trusted and trustworthy third parties. Although private watchdogs can and do help in the process, some form of government chartering and supervision of protection sellers inevitably develops. A principal goal is to protect society from the consequences of aggressive risk-taking, capital shortages, loss concealment, and customer abuse at protection-selling firms. In practice if not in theory, an often unspoken goal is to protect the protection sellers as well.

An over-riding task of financial regulation is to resolve incentive conflicts in financial transactions at minimum net cost to society. The boundaries of an industry's or nation's regulatory system co-evolve with popular perceptions of what financial transactions engender unwelcome social problems. This is what makes crises so impactful. When citizens believe a sector's incentive-control system is working adequately, it is hard to cobble together politically a coalition strong enough to win marked changes in the strategies and tactics used to regulate that sector. This status-quo bias is why changes in regulatory culture are apt to occur only in the wake of large-scale crises. In non-crisis times, lobbying activity can seldom achieve more than 
marginal adjustments either in the objectives that officials pursue or in the character of the policy instruments that officials manipulate within the limits of inherited regulatory norms.

How particular policy strategies actually work in practice is co-determined by the structure of rules that officials promulgate and by regulatees' ability to find and exploit circumventive loopholes in the enforcement of these rules. Exploiting loopholes often entails moving activities from the jurisdiction of traditional overseers who might be equipped and staffed to regulate these activities effectively into the jurisdiction of an agency whose regulatory tools and staff experience render it less qualified to confront the risks and social problems that the innovative products create. To develop cross-agency responses to regulatory arbitrage, the Dodd-Frank Act of 2010 created a multimember interagency Financial Stability Oversight Council (FSOC). But FSOC has yet to frame the issues of jurisdictional migration, regulatory culture and performance risk that concern us here.

\section{II. $\quad$ Links Between Regulatory Norms and Regulatory Machinery}

A culture may be defined as customs, ideas, and attitudes that members of a group share and transmit from generation to generation by systems of subtle and unsubtle rewards and punishments. A regulatory culture is more than a system of rules and enforcement. It incorporates higher-order norms about how officials should comport themselves. These norms limit the ways in which uncooperative or even unscrupulous players can be monitored and disciplined. It includes a matrix of attitudes and beliefs that define what it means for a regulator to use its investigative and disciplinary authority honorably. In effect, these attitudes and beliefs set standards for the fair and efficient use of government power. 
The higher-order social norms that underlie formal regulatory structures penetrate and shape the policy-making process and the political and legal environments within which intersectoral bargaining takes place. Various checks and balances restrain each agency's authority and limit its exercise. Such limits express a distrust of government power that often traces back to abuses observed in a distant past when the country was occupied, colonized, or run by a oneparty government. These underlying standards, taboos, and traditions are normative in two senses. They simultaneously define which behaviors are "normal" and what behaviors regulators should follow to avoid criticism or shame.

In the US, the tools of financial regulation are imbedded in bureaucratic machinery that has four interacting sets of moving parts. Each set is administered respectively by industry, state regulatory bodies, federal agencies, and the courts. The precise machinery, the behavior it controls, and linkages across which different operators interact are organized differently in different financial sectors (e.g., in insurance, banking, securities, and derivatives product lines). Regulatory tools include: chartering, licensing, and registration procedures; disclosure, capital, and liquidity requirements; margin and collateral restrictions; business-conduct rules; stress tests; and administrative orders. Although regulatory toolkits vary within and across the sectors over time, efforts to effect regulatory capture are always and everywhere a potent force.

Prudential regulation imposes on financial regulators a duty to identify and curb excessive risk-taking within their client base and to find and resolve individual-firm insolvencies in a timely fashion. Within any industry or product line, the regulatory culture within which this duty is discharged is spanned by six specific components:

- Legal authority and reporting obligations;

- Formulation and promulgation of specific rules; 
- Burdens of proof regarding the projected benefits and costs of rule changes. (These burdens entail duties of consultation and accountability that guarantee that regulated parties will be treated fairly: i.e., accorded rights of participation and due process);

- Technology for monitoring violation and compliance;

- Penalties for material violations;

- Regulatees' rights to judicial review of regulatory findings and actions (so that intervened parties have access to appeals procedures that serve to bond the fairness guarantee).

As a practical matter, any system of controls generates imbalances in the costs and benefits that accrue to different citizens. Year in and year out, financial industry spokespersons complain about the costs of regulatory compliance and consumer advocates complain about the cost of financial-institution bailouts and instances of abusive activities such as predatory lending or mistreatment of delinquent borrowers.

Social norms subject an agency's disciplinary tactics to intra-governmental checks and balances and require its staff to treat firms that violate its rules or procedures as innocent until proven guilty. These norms also make sure that punishments meted out do not exceed the importance of the behavior being disciplined. As insurance firms such as AIG and Prudential are subjected to bank-like systemic-risk regulation, it is important for federal banking, swaps, and securities regulators to distinguish between efforts to manage an insurance or brokerage firm's risk of contract nonperformance and efforts to control the systemic risks that reflect taxpayers' equity stake in the US safety net. Given the traditional shortsightedness of federal efforts at crisis management, it would be a mistake to assume that efforts to manage the value of the 
government's side of the financial sector's aggregate taxpayer put might not make it harder for retail customers of insurance and brokerage firms to collect funds when they are due.

For both classes of risk management, administrative burdens of proof tend to delay the exercise of regulatory discipline more for undeserving thieves, fraudsters and bumblers than for those whose grievances are legitimate ones. This is because undeserving plaintiffs typically have more at stake. They raise due-process issues to extend the lives and endgame risk-taking of what is apt to be a deeply insolvent firm. Buttressed by the industry's direct and indirect exercise of political clout, regulators' obligation to justify punitive action makes it impossible to impose strong penalties promptly enough to squeeze scams and safety-net subsidies completely out of the system.

Having to establish the fairness and reasonableness of disciplinary actions increases the bureaucratic difficulties of determining that a firm is insolvent and slow the process of resolving insolvencies. Deeply insolvent institutions maliciously delay and shortcircuit disciplinary actions in three ways:

- By delaying write-downs of impaired assets

- By restructuring their operations to move troublesome issues into the jurisdiction of a more-sympathetic or less-wary regulator

- By accumulating political clout and using it to generate (not always proper) interference in disciplinary processes.

\section{The Roots of AIG's Insolvency}

AIG can serve as the poster child for such behavior. Two things made AIG's problems different from other insurance insolvencies. First, at the time of its implosion it had $\$ 1.06$ 
trillion in assets. This made it by far the largest insurance firm in the country. Second, although its traditional life, casualty, and retirement business was supervised by state officials in traditional ways, various "insurance-related activities" morphed out of the jurisdiction of state regulatory regimes. These activities were conducted in opaque subsidiary corporations that transacted with a large number of foreign counterparties. To clarify the regulatory arbitrage this entails, consider the advantages of using a swap to guarantee payments due on a bond. A bond insurance contract would have had to be written by a state-regulated entity. This underwriter would explicitly have to estimate and reserve for the loss exposures generated by its guarantee, establish the existence of an insurable interest on the part of the counterparty (i.e., a long position in the bond), and counterparty claims would be settled over time by assuming the string of future payments specified by the bond contract. Although Dodd-Frank rulemaking might change this, credit default swaps dispensed with these restrictions. Over-the-counter credit default swaps (CDS) market makers like AIG could write contracts with counterparties that had no insurable interest, did not have to document how they reserved for losses, and at settlement would usually be required to come up with a large lump-sum payment.

The highly concentrated risks taken in swap and securities-lending activities would have been hard for state commissioners to reconcile with their traditional concern for policyholder interests had they thought themselves responsible for overseeing them. They took some comfort in the fact that AIG subsidiaries and the firm as a whole were supervised at the consolidated level as a thrift-institution holding company by the Office of Thrift Supervision (OTS). Unfortunately, this regulator lacked both the expertise and the incentives to monitor and control the leverage and volatility inherent in AIG's, burgeoning derivatives and securities-lending businesses. 
AIG illustrates the maxim that firms-like people-are born simple, but die of complications. Corporate complications are both structural and contractual. Table 1, which is taken from Sjostrum (2009), shows how AIG partitioned its activities and that the profitability of AIG's financial-services subsidiaries declined steeply in 2007 and 2008. These losses triggered cash flows and collateral calls in CDS and securities lending programs that AIG proved unable to sustain.

One alleged benefit of segregating different product lines within a holding-company structure is to erect constructive firewalls intended to stop losses in one unit from spreading to other units of the firm. Another is that this arrangement can facilitate the restructuring of the firm if and when it falls into distress. However, neither of these benefits was realized in the AIG debacle. Because top management decisions had not been closely monitored, AIG officials were tempted to use cross-guarantees from the traditional insurance units to lessen the collateral requirements imposed or increase the fees collected on other subsidiaries' deals with swap and securities-lending counterparties. In the absence of interaffiliate guarantees and in states where such guarantees might prove unenforceable, the profits of the insurance units would have stayed positive because counterparties could not have reliably forced the parent to honor claims written against loss-making affiliates. At least arguably, the doctrine of corporate separateness would have allowed the claims of derivatives counterparties to be separated from the insurance units in a prepackaged bankruptcy and given appropriate haircuts.

Both at the Treasury and the Fed, the initial justification for rescuing AIG and keeping its many counterparties whole was not protecting the firm's policyholders and pension-plan participants from nonperformance, but "unusual and exigent circumstances" (i.e., systemic issues) in banking, commercial-paper, and derivatives markets. It was asserted that "a disorderly 
failure of AIG could add to already significant levels of financial market fragility and lead to substantially higher borrowing costs, reduced household wealth, and materially weaker economic performance" (9/16/08 Federal Reserve Press Release cited by Sjostrum, p. 977). The irony is that the system-wide events envisioned were bound to occur whether or not AIG's counterparties were forced to take their lumps in bankruptcy. Because blanket guarantees typically finance negative-value gambles for resurrection, Kane (2009) argues that keeping zombie institutions like AIG in play without eliminating shareholders and subjecting creditors to some level of triage prolongs and intensifies - rather than mitigates - the adverse effects that these firms exert over time on the real economy. The behavior of indices of consumer and business confidence make it likely that Presidential fear-mongering designed to win passage of the Emergency Economic Stabilization Act and curious differences in the extravagance of Treasury and Federal Reserve assistance across the chain of 2008 GSE and investment-firm bailouts created doubts about the competence and sectoral priorities of the nation's top economic officials. Unlike Santa Claus, the Fed and Treasury seemed determined to give their gifts only to firms that had behaved badly.

An authoritative account has yet to emerge of which officials knew what and when they knew it. But as a minimum, state and federal regulators should have noticed that profitability of AIG's financial-services units had been declining for several years at a rate that, thanks to implicit and explicit intracorporate cross-guarantees, threatened its ability to cover in full policyholder and pension claims in its traditional and retirement insurance businesses. The breakdown in supervision was not just that state and OTS personnel failed to observe and curb AIG's growing losses and loss exposures, but that the Fed and counterpart agencies in Europe turned a blind eye to the nonperformance risk that was building up in banking and securities firms that held the other side of AIG's deals. The depth and breadth of the global regulatory 
failure suggest that an unspoken reason for rescuing AIG's creditors and counterparties was bureaucratic blame avoidance. In the US in particular, top officials of a highly unpopular Bush administration could not reasonably expect to hold office beyond January 20, 2009. The rescue's generous treatment of AIG creditors and counterparties converted what would have been immediate industry criticism for being asleep at the wheel into applause for the Treasury's fast action and political bravery and shifted the unpopular task of explicitly financing the rescue forward onto the Fed and succeeding administrations.

\section{IV. $\quad$ Regulation of Insurance Products}

In regulating the insurance industry in the US, federal authorities have remained at the periphery. The McCarran-Ferguson Act of 1945 exempts insurance companies from federal antitrust legislation in ordinary (i.e., noncoercive) circumstances and allows US insurance firms to be chartered and their behavior overseen by agencies of individual states for good (if not sufficient) reasons. In fact, a Federal Insurance Office (FIO) did not even exist until July, 2010 when it was established as part of the Treasury Department by the Dodd-Frank Act. The DoddFrank Act also empowers the multiagency FSOC to classify insurers as "systematically important financial institutions" subject to prudential regulation for their systemic risk by the Federal Reserve.

A strong case can be made for eventually making the FIO into a regulator of reinsurance contracts. But currently it is tasked only with collecting information on the industry and providing advice to other federal bodies on domestic and international insurance matters. Domestically, it will search for gaps and inconsistencies in state regulation and is likely to serve as a channel for touting the advantages of a federal insurance charter to win the expanded 
jurisdiction a federal chartering option would entail. But even if it never gains licensing and supervisory authority, by being able to influence the shape of binding international agreements that promote financial stability, the FIO could eventually force substantial changes in state and industry regulatory machinery.

Among other things, the antitrust exemption is meant to allow firms to share actuarial data and projections as well as to help state insurance commissioners to fix prices and control entry. In practice, industry executives conceive of state insurance regulators as if they were their partners in designing, pricing, and enforcing contract coverages and performance that earn rents (Randall, 1999). The desire to protect these rents may explain why in many circumstances insurance firms allocate capital above and beyond the minimum levels that the state commissioners set.

Recognizing the usefulness of a centralizing authority, state commissioners voluntarily formed a National Association of Insurance Commissioners (NAIC) in 1871. The goals of the NAIC are to assure the solvency of insurers, to protect policyholders, and to create a nationwide regulatory system that preserves state-by-state regulation.

Although the NAIC carefully characterizes itself as a trade association composed of government regulators from different states, Randall (1999) describes it as performing "centralized duties that mirror those of federal regulators in other industries, including the prescription of standard forms for insurance company annual financial statements; the coordination of regional financial examinations of insurance companies; the creation and maintenance of an extensive system of national databases to facilitate state monitoring of insurers and insurance agents; the rating of non-US insurers for the states; the periodic review and accreditation of state insurance departments; the drafting of model laws and regulations, 
many of which have been adopted by state legislatures; the valuation of insurance company investments; training of state insurance regulators; the preparation of statistical reports for state regulators; the assistance to state regulators with technical financial analysis and the assistance to US officials negotiating international trade agreements that concern insurance issues" (Randall, pp. 636-638).

The NAIC is not accountable to voters or subject to direct federal oversight. But its members live in fear of a federal takeover of its centralizing functions. Fanning the flames of this fear is the principal way that federal officials can influence NAIC decision making. Surges in this fear undercut regulatory capture when industry scandal arises. For example, in the late 1980s when a spate of insurance-company insolvencies generated pressure for federal insurance regulation, the NAIC developed and promulgated new standards, information systems, and procedures and tried to impose them on state insurance departments.

Of course, the NAIC is inherently weaker than a federal regulator, in that it lacks the coercive powers of a governmental enterprise. The coercive powers that accrue to the NAIC's commissioner-members do not include the right to compel one another to adopt common laws, standards, or procedures. The result was that the 1980 s effort to force state commissioners to submit to an enhanced NAIC accreditation process did not get very far. The efficacy of this effort was undermined by the absence of further crisis, by industry resistance, and by state legislatures' insistence on preserving their sovereignty from NAIC incursion (Randall, 1999).

Even though state-based supervision of market conduct has proved weak in practice, it has one great advantage. State insurance officials cannot easily supplement the resources of their state guaranty schemes to shift industry losses at state-chartered institutions to state or federal taxpayers. Lacking the power to issue currency, state officials cannot credibly guarantee or 
otherwise support the liabilities of deeply insolvent firms without explicitly budgeting for them by enacting transparent tax increases, raising new debt, or raiding assets set aside as reserves for future expenditures (such as pension obligations). In a crisis, the difficulty of generating state funding keeps expectations of an insurance-industry rescue low unless the Federal Reserve or Treasury can be incentivized to open the spigot of federal support. Except for the bailout of the American International Group (AIG) in September 2008, defaulting obligations of insolvent US insurance firms have in fact been paid from the reserves held in state guaranty funds.

\section{Regulation of Swaps}

Constructively, a swap agreement is a multi-period forward contract between two counterparties. In a swap, the parties agree to exchange cash flows from one hypothetical or "notional" instrument at specified settlement dates for the cash flows from a second designated instrument. Either or both of the instruments may, but need not, have a precise cash-market counterpart. The specified life of the contract is called its "tenor." The two sides of each swap may be regarded as a synthetic incremental balance sheet that renders each counterparty long a series of claims (known as the "receive half") and short a series of obligations (the "pay half"). As a balance sheet, the two halves have a net worth. Because the net worths "derive" from the referenced instruments, swaps are financial derivatives.

But the statutory definition of the term "swap" embraces a broader set of deals than this. It includes, in part, any agreement, contract or transaction "that provides for any purchase, sale, payment or delivery (other than a dividend on an equity security) that is dependent on the 
occurrence, nonoccurrence, or the extent of the occurrence of an event or contingency associated with a potential financial, economic, or commercial consequence."1

Historically, most swaps have been arranged with a third-party dealer or market-maker. This trader collects a fee for lessening the due-diligence and search costs that its customers might otherwise face. The fee may be expressed as a spread between the terms offered for taking up one side or the other of a particular swap. As compared with a brokered market, the customer receives immediate execution and the dealer becomes the counterparty for both sides.

Swaps are financially engineered substitutes for any other intermediated form of indirect finance, forms that themselves serve as substitutes for arrangements that offer direct funding from savers to investors. Whether an individual is a saver or an investor, the opportunity costs encountered in undertaking a swap parallel those met in comparing the benefits and costs of transacting directly with a borrower or saver against using (say) a bank to intermediate the deal. Prudent savers and investors have to assess the differences in the benefits of contracting indirectly and weigh these benefits against the differences in transaction costs. Most households, lack the expertise needed to make direct lending or borrowing the better alternative. Efficient deal-making generates two types of transactions costs: pre-contract shopping, negotiating, and due-diligence expense and post-contract enforcement and unwinding expense.

The dollar value of the cash flows due at each settlement date is calibrated by applying contract terms to a notional principal amount. The contract will also indicate whether differences in the values due at each date are to be settled in cash or in kind.

When the two halves are equally valuable, the swap is said to be "at" or "on" the market. Usually, however, the incremental balance sheet of one counterparty will show positive net worth. That party faces a risk that the party with negative net worth will renege on some or all of

\footnotetext{
${ }^{1}$ CEA Section 1a(47)(A)(ii), 7 U.S.C. 1a(47)(A)(ii).
} 
its obligation. If it were not for this nonperformance risk, one could construct combinations of swap contracts that would reproduce synthetically the exact cash flows generated by any cashmarket portfolio or government-chartered financial intermediary. This means that differences in the dangers of nonperformance (known in the trade as "counterparty risk") are along with systemic risk an essential part of the regulatory problems that swaps and other derivatives pose for society.

Because banking, securities and insurance products have existed for hundreds of years, the dimensions of their regulatory environments have been nailed down in important ways. But because swap contracts are less than a half-century old, their regulatory environment is much more fluid. The volume of interagency rule-making to be completed under the Dodd-Frank Act of 2010 makes the toolkits and language of swaps regulation particularly swampy today.

Prior to the crisis, data on the size of actual and potential imbalances in dealer positions were not readily available. A crisis-engendered G20 agreement seeks to change this by requiring swaps to be centrally cleared and the terms reported to so-called swaps data repositories. In line with this agreement, the Dodd-Frank Act required the Securities and Exchange Commission (SEC) and the Commodities Futures Trading Commission (CFTC) to set rules whose intent is to force swap trading as far as possible onto securities execution facilities (SEFs) and organized exchanges where it would be reported to swaps data repositories (SDRs) and might be monitored and supervised more effectively by government officials. ${ }^{2}$

On an exchange, deals are undertaken jointly by brokers who transmit customer bids and offers to the exchange and by the exchange. As a central clearing party (CCP) the exchange

\footnotetext{
${ }^{2}$ However, although information on swaps is now flowing to the SEC and CFTC, the SDR submissions are incomplete and the resulting data are impossible to aggregate in timely and meaningful fashion. The SDRs claim that it is not their job to police the submissions, while the SEC and CFTC cannot remedy the situation without new rounds of rulemaking.
} 
margins and novates ${ }^{3}$ the trades and accepts the risk that out-of-the-money counterparties may default on the execution date.

Contract performance is supported by broker and exchange due diligence, financial resources, collateral evaluation, and margining procedures. At both the exchange and broker levels, margin and net-worth requirements are set relative to the perceived volume and character of a counterparty's trading activity. Brokers protect themselves by screening customers and margining the value of short sales and pending trades. Exchanges support contract performance further by screening brokers for reputation, competence, and net worth and by holding margin accounts posted by brokers. If, on the execution date, both a customer and its broker fail to complete their half of the trade, the exchange's clearing corporation or partnership must complete the transaction. Efforts to recover the cost of doing this begin with liquidating the assets the defaulting parties have previously posted in margin accounts with them. Shortfalls in a defaulting party's margin account have traditionally been covered from the exchange's guaranty fund, equity, and (where necessary) from special assessments on clearing members.

Across the globe in recent memory, this fail-safe structure has broken down at least three times: in France (1974), in Malaysia (1983), and in Hong Kong (1987). Authorities must recognize that expanding the role of CCPs in derivatives trading increases their systemic importance at the expense of banks and enhances the ability of large CCPs to extract safety-net subsidies from their home government and global hegemons. The rest of the paper builds on my belief that the US agencies the DFA makes responsible for overseeing CCPs (the SEC and CFTC) lack the focus, expertise, experience, and resources to manage adequately the way that swaps transactions affect US taxpayers' equity position in global safety nets and that banking

\footnotetext{
${ }^{3}$ A contract is "novated" when the original two-party contract is torn up and replaced by two new contracts in which responsibility for the separate contractual obligations and rights of each party is transferred in whole to the novator.
} 
regulators are fooling themselves in thinking that conscientiously monitoring accounting capital at banks and financial holding companies will accomplish this task.

\section{Rethinking Efforts to Control Systemic Risk}

The existence of safety-net guarantees creates a loss-absorbing contra-liability for complex mega-institutions that economists describe as a "taxpayer put." Even in quiet times, the put makes private equity and debt funding available to entities that are perceived to be DTU at lower cost and in larger amounts than would otherwise be available. During the recent crisis, guarantees were pushed farther beyond statutory and national limits than ever before. Moreover, the Fed's right to extend loans to firms headquartered in other countries when unstable market conditions exist has been made explicit by the Dodd-Frank Act.

Around the world, governments are finally acknowledging that complex megainstitutions receive near-perfect guarantees, but the existence and value of the corresponding contra-liability are not currently recognized in law or accounting practice, nor are its effects clearly understood by the taxpayers who provide it. This lack of recognition facilitates amoral and felonious profiteering at firms who have access to the put.

Government officials are encouraging mega-institutions to simplify their organizations (Adler, 2014). But they seem unwilling to punish these firms and their managers commensurately for willfully expanding the value of safety-net guarantees in ways that unjustly enrich themselves at taxpayer expense. Because modern legal theory characterizes corporations as persons, giant holding companies could be prosecuted and convicted for engaging willfully either in securities fraud or even in what I call "theft by safety net" (Kane, 2014). Achieving a few such convictions would dramatically change the costs and benefits of safety-net abuse and 
lessen competitive inequities by reversing regulation-induced increases in the size and complexity of the country's largest financial holding companies. This is because convicted felons cannot own insured commercial banks or be licensed to function as broker-dealers or futures commission merchants.

The failure to characterize the nature and consequences of safety-net support correctly in law and in public discussion leaves the door open to shady and hard-to-monitor behaviors that increase the value of the put. These behaviors should be monitored more directly in the future and their legal boundaries deserve to be carefully remapped. These activities include but are not limited to:

- Regulatory capture (deliberately sewing loopholes into statutes, rules, and enforcement procedures);

- Influencing the funding and staffing of regulatory agencies;

- Exploiting jurisdictional gaps and ambiguities;

- Persuading politicians and regulators to favor domestic institutions unfairly over foreign ones;

- Using innovative financial institutions and contract forms to bypass or reduce reporting and other supervisory burdens.

Legal categories and definitions will always lag financial realities because the regulated are more adept at taming and gaming changes in regulators' rules than the regulators are at understanding and adapting to financial innovation. Long time lags exist between the first occurrence of activities that exploit the put and adequate legislative and regulatory responses to them. In recent years, mega-institutions have been generating urgent new problems even before 
old ones are fully addressed. Many of these new problems cross international boundaries in ways that serve to multiply loophole opportunities and regulatory conflicts of interest.

The DFA sets out more than a dozen characteristics that FSOC must use in determining whether non-bank firms are deemed systemically important financial institutions (SIFIs). Listing so many characteristics creates unnecessary discretion that invites political manipulation. Measuring systemic risk by the value of a firm's taxpayer put provides a more concrete and accountable way for FSOC to determine who is and is not a SIFI.

The DFA and Basel III treat the symptoms of supervisory breakdown, but not the conditions that bring the symptoms about. These alleged regulatory remedies measure risk exposures a tad more accurately, but falsely suppose that instability can be cured by adjustments in formal structures of regulation and supervision without also enhancing procedures for monitoring and punishing safety-net abuse. A nice first step would be to classify corporate and personal safety-net abuse as criminal behavior per se and require the Department of Justice to prosecute this crime. 
TABLE 1

SOURCES OF AIG PROFIT AND LOSS, 2005 THROUGH SEPTEMBER 30, 2008

\begin{tabular}{|c|c|c|c|c|}
\hline (in millions) & $\begin{array}{l}\text { Nine Months } \\
\text { Ended } \\
9 / 30 / 08\end{array}$ & 2007 & 2006 & 2005 \\
\hline \multicolumn{5}{|l|}{ Revenues } \\
\hline General Insurance & $\$ 35,854$ & $\$ 51,708$ & $\$ 49,206$ & $\$ 45,174$ \\
\hline $\begin{array}{l}\text { Life Insurance \& } \\
\text { Retirement }\end{array}$ & 14,271 & 53,570 & 50,878 & 48,020 \\
\hline Financial Services & $(16,016)$ & $(1,309)$ & 7,777 & 10,677 \\
\hline Asset Management & 658 & 5,625 & 4,543 & 4,582 \\
\hline Other & 531 & 457 & 483 & 344 \\
\hline $\begin{array}{l}\text { Consolidation \& } \\
\text { Eliminations } \\
\end{array}$ & (436) & 13 & 500 & (16) \\
\hline Total & $\$ 34,862$ & $\$ 110,064$ & $\$ 113,387$ & $\$ 108,781$ \\
\hline \multicolumn{5}{|l|}{$\begin{array}{l}\text { Operating Income } \\
\text { (Loss) }\end{array}$} \\
\hline General Insurance & $\$(393)$ & $\$ 10,562$ & $\$ 10,412$ & $\$ 2,315$ \\
\hline $\begin{array}{l}\text { Life Insurance \& } \\
\text { Retirement }\end{array}$ & $(19,561)$ & 8,186 & 10,121 & 8,965 \\
\hline Financial Services & $(22,880)$ & $(9,515)$ & 383 & 4,424 \\
\hline Asset Management & $(2,709)$ & 1,164 & 1,538 & 1,963 \\
\hline Other & $(2,899)$ & $(2,140)$ & $(1,435)$ & $(2,765)$ \\
\hline $\begin{array}{l}\text { Consolidation \& } \\
\text { Eliminations } \\
\end{array}$ & 237 & 722 & 668 & 311 \\
\hline Total & $\$(48,205)$ & $\$ 8,943$ & $\$ 21,687$ & $\$ 15,213$ \\
\hline
\end{tabular}

Source: Sjostrum (2009), p. 947. 


\section{REFERENCES}

Adler, Joe, 2014. “OCC Pushing to Simplify Big Banks," American Banker (March 1), 1 and 3.

Kaiser, Robert G., 2013. Act of Congress: How America's Essential Institution Works and How It Doesn't. New York, Vintage Books.

Kane, Edward J., 2005. "Confronting Divergent Interests in Cross-Country Regulatory Arrangements," Reserve Bank of New Zealand Bulletin, 69(3), 5-17. , 2009. "Incentive Roots of the Securitization Crisis and Its Early Mismanagement," Yale Journal on Regulation, 26, 405-416. , 2010. "Redefining and Containing Systemic Risk," Atlantic Economic Journal, 38, 251-264. , 2014. "Shadowy Banking: Theft by Safety Net," Yale Journal on Regulation (forthcoming).

Randall, Susan, 1999. "Insurance Regulation in the United States: Regulatory Federalism and the National Association of Insurance Commissioners," Florida State University Law Review, 26, 625-699.

Sjostrum, William K., Jr., 2009. “The AIG Bailout,” Washington \& Lee Law Review, 66, 943991. 